\title{
The impact of cigarette dependence severity on disease outcomes and depression in ankylosing spondylitis
}

\author{
Seyhan Dülger ${ }^{1}$, İlknurAykurt Karlıbel ${ }^{2}$, Tekin Yıldız ${ }^{1}$, Lale Altan² ${ }^{2}$ Özlem Şengören Dikiş ${ }^{1}$, Meliha \\ Kasapoğlu Aksoy²
}

${ }^{1}$ Department of Chest Diseases, University of Health Sciences, Bursa Yüksek Ihtisas Training and Research Hospital, Bursa, Turkey ${ }^{2}$ Department of Physical Medicine and Rehabilitation, University of Health Sciences, Bursa Yüksek Ihtisas Training and Research Hospital, Bursa, Turkey

DOI: $10.18621 /$ eurj.336935

\begin{abstract}
Introduction: Ankylosing spondylitis (AS) is a chronic systemic inflammatory disease. Smoking plays a role in AS pathogenesis and causes difficulties in its treatment. The aim of this study is to investigate the association of disease activity, functional status, spinal mobility, depression, chest expansion, pain, fatigue, quality of life, respiratory function with cigarette dependence severity in patients with AS.

Methods: The study included 71 patients diagnosed as AS. Patients were evaluated on questionnaires and examination scales specific to assessment of AS. The results were compared using the SPSS-23 software. Results. Out of the total 71 patients, 40 (56.3\%) were smokers, 31 (43.7\%) were non-smokers. There were no significant differences between the smokers and the non-smokers with respect to the median values in Bath Ankylosing Spondylitis Disease Activity Index, Bath Ankylosing Spondylitis Metrology Index (BASMI), Bath Ankylosing Spondylitis Functional Index, Ankylosing Spondylitis Quality of Life questionnaire, Short Form 36 (SF-36), chest expansion, the fingertip-to-floor test and Beck Depression Inventory $(p>0.05)$. However, there were significant differences when comparing the median scores on BASMI $(p=0.036)$, SF-36 physical role strength $(p=0.004)$ and the chest expansion $(p=0.015)$ of the smoker patients placed in the three Fagerström Test for Nicotine Dependence (FTND) subgrouping.

Conclusion: AS patients with smoking have elevated FTND scores and worse values for test of disease activity and quality of life.
\end{abstract}

Keywords: Smoking, ankylosing spondylitis, life quality

Received: September 6, 2017; Accepted: December 14, 2017; Published Online: February 24, 2018

A nkylosing spondylitis (AS) is a chronic systemic inflammatory disease mainly characterised with symptoms in the sacroiliac and peripheral joints and the spine [1]. Back pain, stiffness, difficulty of spinal movements and fatigue are the main symptoms of the disease [2]. AS prevalence has been reported within the range of $0.1 \%-1.4 \%$ [3]. Total cure of AS with drugs has not yet been achieved therefore, treatment consists of controlling the spinal inflammation and preventing movement limitation and pain [4]. In population based study, incident AS was found associated with current smoking [5]. Smoking has been associated with increased disease activity, functional impairment and low quality of life in AS [6-8]. We have not been able to find out about the relationship between severities of cigarette addiction

Address for correspondence: Seyhan Dülger, MD., University of Health Sciences, Bursa Yüksek Ihtisas Training and Research Hospital, Department of Chest Diseases, Emniyet Caddesi No:35, 16115 Yıldırım, Bursa, Turkey

E-mail:drsdulger@gmail.com,Phone:+902244526648 
with AS outcomes, despite there were studies what is associated with cumulative smoking history and disease activity.

The aim of this study is to investigate the association of disease activity, functional status, spinal mobility, depression, chest expansion, pain, fatigue, quality of life, respiratory function with cigarette dependence severity in patients with AS

\section{METHODS}

AThe study was conducted in accordance with the recommendations of the Helsinki Declaration and was approved by the Bursa Yuksek Ihtisas Training and Research Hospital Ethical Committee (2016/11-04). Written informed consent was obtained from all participants before undertaking any study-related procedures.

The study included 71 individuals diagnosed as AS on the Modified New York criteria and placed under follow up at the Physical Medicine and Rehabilitation Clinic. The exclusion criteria of the study were being outside the age range of 18-65 years, and having chronic systemic diseases such as hypertension, diabetes mellitus, chronic obstructive pulmonary disease (COPD) and renal failure.

\section{Evaluation parameters}

Bath Ankylosing Spondylitis Disease Activity Index (BASDAI): Patient fatigue, axial pain, peripheral pain, morning imprisonment, disturbance resulting from touching and repression, and general discomfort of the patient are marked on a horizontal visual analogue of $10 \mathrm{~cm}$. The total BASDAI score of the patient varying between $0-10$ is calculated [9].

Bath Ankylosing Spondylitis Metrology Index (BASMI): Cervical rotation, tragus-wall distance, lateral flexion, modified Schober and intermalleolar distance are the 5 best clinical measurements that best reflect the axial state. The sum of transformed points of each measurement is calculated. The score is between 5-15, and describes the disease state in AS. The BASMI is rapid ( $7 \mathrm{~min}$.), reproducible and susceptible to change in the disease spectrum. The lower score shows a better level [10].

Bath Ankylosing Spondylitis Functional Index (BASFI): It is a measure of 10 questions designed to determine the degree of functional restriction in patients with AS. Each question is answered on a 10 $\mathrm{cm}$ horizontal visual analogue scale and their average gives the BASFI score (0-10) [11].

Ankylosing Spondylitis Quality of Life questionnaire (ASQol): It is a measure of the quality of life of the patients by questioning each question with a yes or no answer over 18 questions. The sum of the yards gives the score. It is a good, reliable method $[12,13]$.

Short Form 36 (SF-36): For measure of thirty-six questions that assesses the condition of the illness and loss of power Short Form 36 was done. Eight subparameters consisting of physical function (SF-PF), physical role strength (SF-PRS), emotional role strength (SF-ERS), power / live / vitality SF-PLV), emotional health SF-EH), social functioning (SF-SF), pain (SF-P) and general health perception (SF-GHP) are calculated by scoring these questions. High scores show a better level of health [14].

Chest Expansion: The difference is measured by measuring the chest diameter during maximum inspiration and maximum expiration [15].

The Fingertip-to-Floor Test (FTFT): The patient should stand comfortably with his feet pointing forward and be asked to lean forward. He tries to touch his fingertips with his fingers without twisting his knees. The distance between the floor and the fingertips is measured [16].

Beck Depression Inventory (BDI): Multiple choice 21 questions is a tool used to measure the severity of depression. In addition to pessimism, past failures and mistakes, guilt feelings, penalizing feelings, selfesteem, self-criticism, suicidal thoughts and worthless feelings besides sadness, pleasure loss, crying, agitation, indifference, indecision, energy loss, change in sleep patterns, somatic findings such as difficulties in concentration, fatigue, loss of sexual appetite are also examined. Each question is evaluated between 0 3 points [17].

Fagerström Test for Nicotine Dependence (FTND): The cigarette smoking AS patients were further evaluated with the Fagerström Test for Nicotine Dependence (FTND) [18]. FTND is standard tool for assessing Nicotine Dependence. It consists of six questions evaluating smoking. Dependence value is calculated by scoring from 1 to 10 [18]. Patients were mildly between $1-4$ points; $5-7$ points moderate; 
8-10 points were divided into subgroups dependent on severe.

Measurement of Carbon Monoxide in Expiratory Air (Exp. CO): Exp.CO is (PICO Smokerlyzer (PICO SmokerlyzerRBedfont Micro Breath Alyzer, Kent, United Kingdom) device was used. The measurements were evaluated in terms of parts per million (ppm). The cut off level was determined as 6 ppm CO [19]. HLA-B27 was recorded. Flow cytometry method was used for HLA-B27. Nonsteroidal anti-inflammatory drugs (NSAIDs), disease-modifying antirheumatic drugs (Dmard) and tumor necrosis factor alpha inhibitor (TNF $\alpha$-inh) used by patients were noted.

\section{Statistical Analysis}

The data of the cigarette smoker and non-smoker patients accumulated on the questionnaires and measurements were compared using the Statistical Package for Social Sciences (SPSS) (IBM Corp. Released 2015. IBM SPSS Statisticsfor Windows, Version 23.0. Armonk, NY: IBM Corp.). Numerical values were expressed by the mean and the standard deviation; and their distribution was tested with the
Kolmogorov-Smirnov test. Categorical values were evaluated with percentages. Comparison of the mean values were carried out using the Student-t Test, the Kruskal-Wallis Test and the Mann-Whitney U Test. Relationships were tested using the Spearman correlation test. The $p<0.05$ values were accepted to indicate statistical significance.

\section{RESULTS}

The cigarette smokers constituted $56.3 \%(n=40)$ of the 71 patients included in the study, while $43.7 \%$ $(\mathrm{n}=31)$ were non-smokers. Demographic findings, education, income, smoking habits, spirometer parameters, HLA-B27, drug use, disease symptoms and diagnostic periods of smokers and non-smokers were given in Table 1 . Two (5\%) smokers and one $(3.2 \%)$ non-smoker were not taking any medication. Six $(15 \%)$ smokers and three $(9.7 \%)$ non-smokers were using two different medications. Statistically significant differences between the smokers and the non-smokers were not observed with respect to the

Table 1. Patient and disease characteristics in smokers and nonsmokers

\begin{tabular}{|c|c|c|c|c|c|}
\hline & & $\begin{array}{c}\text { ALL } \\
(n=71)\end{array}$ & $\begin{array}{c}\text { SMOKER } \\
(n=40)\end{array}$ & $\begin{array}{c}\text { NON-SMOKER } \\
(n=31)\end{array}$ & $p$ value \\
\hline \multirow[t]{2}{*}{ Gender } & Male & $55(77.5)$ & $29(72.5)$ & $26(83.9)$ & \multirow[t]{2}{*}{$0.255^{\mathrm{a}}$} \\
\hline & Female & $16(22.5)$ & $11(27.5)$ & $5(16.1)$ & \\
\hline Age (year) & & $38(18-68)$ & $37(18-57)$ & $38(22-63)$ & $0.391^{\mathrm{b}}$ \\
\hline BMI & & $25.08(19-37)$ & $25.27(19-37)$ & $24.97(19-34)$ & 0.963 \\
\hline \multirow[t]{3}{*}{ Education } & Primary school & $43(60.6)$ & $21(52.5)$ & $22(71)$ & \multirow[t]{3}{*}{$0.283^{\mathrm{a}}$} \\
\hline & High school & $10(14.1)$ & $7(17.5)$ & $3(9.7)$ & \\
\hline & University & $18(25.4)$ & $12(30)$ & $6(19.4)$ & \\
\hline \multirow[t]{3}{*}{ Pay } & none & $24(33.8)$ & $14(35)$ & $10(32.3)$ & \multirow[t]{3}{*}{$0.242^{\mathrm{a}}$} \\
\hline & $\leq$ minimum wage & $25(35.2)$ & $11(27.5)$ & $14(45.2)$ & \\
\hline & $>$ minimum wage & $22(31)$ & $15(37.5)$ & $7(22.5)$ & \\
\hline NSAID & & $38(46.5)$ & $20(50)$ & $13(41.9)$ & $0.499^{\mathrm{a}}$ \\
\hline Dmard & & $33(46.5)$ & $16(40)$ & $17(54.8)$ & $0.214^{\mathrm{a}}$ \\
\hline TNFo-inh & & $11(15.5)$ & $8(20)$ & $3(9.7)$ & $0.327^{\mathrm{a}}$ \\
\hline Symptom time (years) & & $10(1-37)$ & $10(5-32)$ & $12(1-37)$ & $0.071^{\mathrm{b}}$ \\
\hline Diagnosis time (years) & & $4(1-37)$ & $3(1-32)$ & $5(1-37)$ & $0.283^{b}$ \\
\hline HLA-B27 & & $47(66.2)$ & $23(57.5)$ & $24(77.4)$ & $0.078^{\mathrm{a}}$ \\
\hline \multirow[t]{3}{*}{ FTND } & Mild & - & $10(25)$ & - & \multirow[t]{3}{*}{-} \\
\hline & Moderate & - & $15(37.5)$ & - & \\
\hline & Severe & - & $15(37.5)$ & - & \\
\hline $\begin{array}{l}\text { Cumulative Smoking } \\
\text { (pocket/year) }\end{array}$ & & - & $10(1-49)$ & - & - \\
\hline $\operatorname{Exp.CO}(p p m)$ & & - & $6.5(0-24)$ & - & - \\
\hline
\end{tabular}

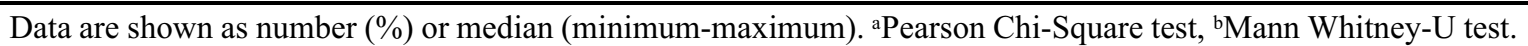
$\mathrm{BMI}=$ Body mass index, Dmard $=$ disease-modifying antirheumatic drugs, Exp. $\mathrm{CO}=$ Carbon Monoxide in Expiratory Air, FTND = Fagerström Test for Nicotine Dependence, NSAIDs $=$ Nonsteroidal anti-inflammatory drugs, TNF $\alpha$-inh $=$ tumor necrosis factor alpha inhibitor 
mean values of BASDAI, BASFI, BASMI, the SF-36 subsections (SF-PF, SF-PRS, SF-ERS, SF-PLV, SFEH, SF-SF, SF-P, SF-GHP), ASQol, VAS PAIN (0-100), VAS Fatigue (0-100), the BDI score, chest expansion, FTFT, ESR level, and the CRP level ( $p>$ 0.05)(Table 2).

Comparison of parameters according to severity of dependence (FTND test) is shown in Table 3. There were significant differences when comparing the median scores on BASMI ( $p=0.036)$, SF-36 physical role strength $(p=0.004)$ and the chest expansion $(p=$ $0.015)$ of the smoker patients placed in the three FTND subgrouping. When, however, the mean values of the disease activity and life quality data of the smoking patients with FTND scores of $\leq 4$ and FTND $>4$ were compared with the corresponding data of the smoking patients, the mean SF-PRS and SF-EH scores of the FTND $=5-10$ patients were significantly lower than those of FTND $\leq 4(p=0.029$ and $p=0.045$, respectively).

There was correlation between Exp. $\mathrm{CO}$ and FTFT; Exp. CO and BASFI $(r=0.280 ; p=0.022$ and $\mathrm{r}=0.277 ; p=0.022$, respectively). A correlation was found between SF-PRS and the FTND; Cumulative Smoking (pocket/year) and FTND; Exp. CO And FTND $(\mathrm{r}=0.319 ; p=0.045, \mathrm{r}=0.654 ; p<0.001$ and $\mathrm{r}=0.344 ; p=0.03$, respectively). Correlation of BDI with other parameters was shown in Table 4.

\section{DISCUSSION}

This The most significant result of our study was the determination of a trend of worsening in the BASMI, SF-PRS and chest expansion data with the severity of nicotine dependence in AS patients. The mean SF-PRS and SF-EH scores of AS patients with mild nicotine dependence were significantly higher as compared to those of the patients with moderate or severe dependence. Also, Exp. CO with BASFI, FTND and FTFT were found to be correlated. There are reports on a worse course of AS in smoking as compared to the non-smoking patients [8, 20-22]. To the best of our knowledge, in our study we

Table 2. Disease activity, quality of life and spinal immobility in smokers and non-smokers

\begin{tabular}{|c|c|c|c|c|c|}
\hline & & $\begin{array}{c}\text { ALL } \\
(n=71)\end{array}$ & $\begin{array}{c}\text { SMOKER } \\
(\mathrm{n}=40)\end{array}$ & $\begin{array}{c}\text { NON-SMOKER } \\
(n=31)\end{array}$ & p value \\
\hline BASDAI & & $4.7(0-10)$ & $4.5(0-8.4)$ & $4.8(0-10)$ & $0.289^{b}$ \\
\hline BASFI & & $3.8(0-9.5)$ & $3.7(0-8)$ & $4.2(0-9.5)$ & $0.190^{\mathrm{b}}$ \\
\hline BASMI & & $7(5-15)$ & $6(5-15)$ & $7(5-15)$ & $0.260^{\mathrm{b}}$ \\
\hline CRP (mg/l) & & $\begin{array}{c}4.12(0- \\
41.8)\end{array}$ & $4(0-39.3)$ & $4.6(3.1-41.8)$ & $0.429^{\mathrm{b}}$ \\
\hline $\operatorname{ESR}(\mathbf{m m} / \mathbf{h})$ & & $13.5(2-76)$ & $14(2-76)$ & $13(2-51)$ & $0.434^{\mathrm{b}}$ \\
\hline ASQol & & $10(0-18)$ & $9(0-17)$ & $11(0-18)$ & $0.119^{b}$ \\
\hline Chest Expansion & & $4(1-9)$ & $5(1-9)$ & $4(1-7)$ & $0.143^{\mathrm{b}}$ \\
\hline FTFT & & $23.5(0-65)$ & $20(0-47)$ & $24(0-65)$ & $0.253^{\mathrm{b}}$ \\
\hline \multirow[t]{8}{*}{ SF-36 } & Physical Function & $65(0-100)$ & $67.5(10-100)$ & $55(0-95)$ & $0.227^{\mathrm{b}}$ \\
\hline & $\begin{array}{l}\text { Physical Role } \\
\text { Strength }\end{array}$ & $12.5(0-75)$ & $37.5(0-75)$ & $12.5(0-50)$ & $0.105^{\mathrm{b}}$ \\
\hline & $\begin{array}{l}\text { Emotional Role } \\
\text { Strength }\end{array}$ & $16.7(0-100)$ & $16.7(0-100)$ & $16.7(0-50)$ & $0.827^{\mathrm{b}}$ \\
\hline & Power/Live/Vitality & $40(0-100)$ & $40(10-100)$ & $40(0-90)$ & $0.589^{\mathrm{b}}$ \\
\hline & Emotional Health & $56(4-100)$ & $48(24-100)$ & $56(4-84)$ & $0.940^{\mathrm{b}}$ \\
\hline & Social Functioning & $62.5(0-100)$ & $62.5(0-100)$ & $62.5(0-100)$ & $0.397^{\mathrm{b}}$ \\
\hline & Pain & $45(0-100)$ & $45(0-100)$ & $45(0-100)$ & $0.571^{\mathrm{b}}$ \\
\hline & $\begin{array}{l}\text { General Health } \\
\text { Perception }\end{array}$ & $30(0-100)$ & $30(0-100)$ & $31(0-85)$ & $0.697^{\mathrm{b}}$ \\
\hline BDI & & $16(0-45)$ & $14.5(0-39)$ & $19(5-45)$ & $0.304^{\mathrm{b}}$ \\
\hline
\end{tabular}

Data are shown as median (minimum-maximum). ${ }^{a}$ Pearson Chi-Square test, ${ }^{b}$ Mann Whitney-U test. ASQol = Ank Spondylitis Quality of Life questionnaire, BASDAI = Bath Ankylosing Spondylitis Disease Activity Index, BASFI Ankylosing Spondylitis Functional Index, BASMI = Bath Ankylosing Spondylitis Metrology Index, BDI $=$ Beck Dep Inventory, $\mathrm{CRP}=\mathrm{C}$-reactive protein, $\mathrm{ESR}=$ erythrocyte sedimentation rate, FTFT $=$ the fingertip-to-floor test, $\mathrm{S}$ Short Form 36 
Table 3. Comparison of parameters according to severity of dependence

\begin{tabular}{|c|c|c|c|c|c|}
\hline & & MILD & MODERATE & SEVERE & $p$ value* \\
\hline BASDAI & & $4.6(0-8)$ & $5(1-8.3)$ & $4(1.1-8.4)$ & 0.659 \\
\hline BASFI & & $2.6(0-6.1)$ & $4.9(0-8)$ & $1.8(0-7.8)$ & 0.405 \\
\hline BASMI & & $6(5-15)$ & $8(5-14)$ & $6(5-15)$ & 0.036 \\
\hline CRP (mg/l) & & $5.5(0.3-39.3)$ & $3.2(3.1-29)$ & $5.2(0-18.7)$ & 0.490 \\
\hline $\operatorname{ESR}(\mathbf{m m} / \mathbf{h})$ & & $19.5(2-76)$ & $13(6-58)$ & $13.5(2-36)$ & 0.496 \\
\hline ASQol & & $8(0-16)$ & $11(0-16)$ & $7(0-17)$ & 0.643 \\
\hline Chest Expansion & & $5(2-7)$ & $3.5(1-7)$ & $6(2-9)$ & 0.015 \\
\hline FTFT & & $13.5(0-34)$ & $25(5-42)$ & $20(0-47)$ & 0.382 \\
\hline \multirow[t]{8}{*}{ SF-36 } & Physical function & $65(0-100)$ & $55(20-100)$ & $75(10-95)$ & 0.508 \\
\hline & physical role strength & $25(0-50)$ & $12.5(0-37.5)$ & $37.5(0-62.5)$ & 0.004 \\
\hline & emotional role strength & $25(0-50)$ & $16.7(0-50)$ & $16.7(0-100)$ & 0.714 \\
\hline & power/live/vitality & $35(15-100)$ & $40(10-85)$ & $50(10-90)$ & 0.820 \\
\hline & emotional health & $62(40-100)$ & $48(24-100)$ & $44(28-96)$ & 0.245 \\
\hline & social functioning & $75(0-100)$ & $50(12.5-100)$ & $62.5(25-100)$ & 0.928 \\
\hline & pain & $40(0-90)$ & $45(0-100)$ & $67.5(0-90)$ & 0.965 \\
\hline & $\begin{array}{l}\text { general health } \\
\text { perception }\end{array}$ & $30(15-100)$ & $25(0-90)$ & $45(15-75)$ & 0.248 \\
\hline BDI & & $14.5(0-28)$ & $14(5-39)$ & $19(0-37)$ & 0.632 \\
\hline
\end{tabular}

Data are shown as median (minimum-maximum). *Kruskal-Wallis test. ASQol = Ankylosing Spondylitis Quality of Life questionnaire, BASDAI = Bath Ankylosing Spondylitis Disease Activity Index, BASFI = Bath Ankylosing Spondylitis Functional Index, BASMI = Bath Ankylosing Spondylitis Metrology Index, BDI = Beck Depression Inventory, $\mathrm{CRP}=\mathrm{C}$-reactive protein, $\mathrm{ESR}=$ erythrocyte sedimentation rate, $\mathrm{FTFT}=$ the fingertip-to-floor test, $\mathrm{SF}$ $36=$ Short Form 36

demonstrate the relationship between the disease activity and quality of life, the severity of nicotine dependence and the Exp. CO level in the cigarette smoking AS patients. Zhao et al. [8], who studied cumulative smoking and disease activity in AS, found BASFI 2.1 higher in heavy smokers (21-40 packyears). For cumulative smoking was correlated with FTND and Exp. CO in our study, we indirectly supported Zhao et al. [8]. However, although they found that BASDAI was 1.6 higher in heavy smokers, BASDAI among our FTND subgroups was not statistically significant. It's reported that, BASDAI and BASFI were found to be higher in smokers than non-smokers [23-25]. However, Zhao et al. [8] did not found difference between smoker and nonsmoker patients' BASDAI and BASFI values like with us. BASMI, chest expansion and FTFT were tests which shown physical mobility in AS. Chung et al. [25] did not find different BASMI between the smokers and nonsmokers patients. These findings were in accordance with our results. On the other hand, Zhang et al. [21] reported that smoker patients' BASMI was higher than non-smoker patients. It seems that for the BASMI values of smoking and non-smoking AS patients, there is no consensus among studies. In some studies chest expansion found lower in smokers with AS [26]. However, according to Averns et al. [27], chest expansion was not different between AS and non-smoker patients. Zhang et al. [21] reported that FTFT was statistically significant differences between smoker and non-smoker patients with AS. In contrast, Chen et al. [26], Averns et al. [27] and we did not find any significant difference between the smokers and non-smokers.

We used ASQoL and SF-36 tests to assess the quality of life of our patients. ASQoL was not differences between the smoker and non-smoker patients in our study. However, in previous studies, it was observed to be poorer in smokers [7, 23, 28]. SF36 was associated with smoking by Chung et al. [25]. In contrast, Bodur et al. [28] found no significant differences in SF-36 among smokers and nonsmokers.

In the study of Esen et al. [29], it was taken to attention that depression was frequently associated with the disease in chronic pain-related diseases. BDI of AS patients were found to be higher than control group in this study. We also determined the correlation between disease activity, physical mobility and quality of life-related parameters and BDI. There was no 
Table 4. Correlation of BDI with other parameters

\begin{tabular}{|c|c|c|c|}
\hline & & $p$ & $\mathbf{r}$ \\
\hline BASDAI & & $<0.001$ & $0.553^{*}$ \\
\hline BASFI & & $<0.001$ & $0.518^{*}$ \\
\hline BASMI & & 0.003 & $0.342 *$ \\
\hline ASQoL & & $<0.001$ & $0.719 *$ \\
\hline Chest Expansion & & 0.029 & $-0.262 *$ \\
\hline FTFT & & 0.001 & $0.378 *$ \\
\hline \multirow[t]{8}{*}{ SF-36 } & Physical function & $<0.001$ & $-0.612 *$ \\
\hline & physical role strength & 0.295 & -0.126 \\
\hline & emotional role strength & $<0.001$ & $-0.536^{*}$ \\
\hline & power/live/vitality & $<0.001$ & $-0.565^{*}$ \\
\hline & emotional health & $<0.001$ & $-0.626^{*}$ \\
\hline & social functioning & $<0.001$ & $-0.591 *$ \\
\hline & pain & $<0.001$ & $-0.563 *$ \\
\hline & general health perception & $<0.001$ & $-0.552^{*}$ \\
\hline Smoking & & 0.308 & -0.123 \\
\hline FTND & & 0.484 & 0.114 \\
\hline Exp. CO & & 0.111 & 0.195 \\
\hline
\end{tabular}

*Correlation is significant. Correlation coefficient (r), Spearman correlation test was used. ASQol = Ankylosing Spondylitis Quality of Life questionnaire, BASDAI = Bath Ankylosing Spondylitis Disease Activity Index, BASFI = Bath Ankylosing Spondylitis Functional Index, BASMI = Bath Ankylosing Spondylitis Metrology Index, BDI = Beck Depression Inventory, Exp. $\mathrm{CO}=$ Carbon Monoxide in Expiratory Air, FTFT = the fingertipto-floor test, FTND = Fagerström Test for Nicotine Dependence, SF-36 = Short Form 36

significant difference in our study between smokers and non-smokers. However, the median value of nonsmoker patients was slightly higher. Perhaps this is why we do not find BASDAI, BASFI, BASMI, ASQoL and SF-36 different in smoker patients with AS. The values that could be expected to be better in non-smokers were covered by depression. In addition, this may have been due to the relatively small numbers of patients included in the study.

HLA-B27 positivity has a role in the pathogenesis of AS. Several studies have also been reported concerning the relationship between HLA-B17 and Interleukin-17 (IL-17) production [30]. There is also a link between IL-17 and cigarettes [6]. All these may suggest that smoking together with HLA-B27 may have an impact on the pathogenesis and activation of AS. HLA-B27 positivity was found as $62.7 \%$ of AS patients. It was reported that, in other studies, this rate was given as $48.5 \%$ and $85.3 \%$, respectively $[5,31]$. Our result is consistent with previous studies.

\section{The Limitations of the Study}

The main limitation to our study is the small number of patients investigated. Division of the patient population as the smokers and non-smokers, with further subgrouping of the smoking patients on grounds of the severity of nicotine dependence result in a decrease of the number of patients in each category and this is assumed to affect the statistical evaluations. In addition, our study did not evaluate exsmoker patients with AS.

Also, it has not been possible to follow-up for an adequate period the response to therapy of the smoking AS patients. The results indicate that after advising a larger population of patients to give up smoking, data on disease activity and quality of life in the smokers and the non-smokers need to be investigated.

\section{CONCLUSION}

In this study, significant differences between smoker and non-smoker AS patients on grounds of disease activity and quality of life were not observed. However, that smoker AS patients with elevated FTND scores had worse values for test of disease activity and quality of life. It is believed that, treatment of the cigarette smoking AS patients for the cessation of the smoking habit should be part of the routine therapy. 


\section{Conflict of interest \\ The authors disclosed no conflict of interest during the preparation or publication of this manuscript.}

\section{Financing \\ The authors disclosed that they did not receive any grant during conduction or writing of this study.}

\section{REFERENCES}

[1] Zhang S, Li Y, Deng X, Huang F. Similarities and differences between spondyloarthritis in Asia and other parts of the World. Curr Opin Rheumatol 2011;23:334-8.

[2] O'Dwyer T, Monaghan A, Moran J, O'Shea F, Wilson F. Behaviour change intervention increases physical activity, spinal mobility and quality of life in adults with ankylosing spondylitis: a randomised trial. J Physiother 2017;63:30-9.

[3] Braun J, Sieper J. Ankylosing spondylitis. Lancet 2007;369:137990

[4] Braun J, Brandt J, Listing J, Alten R, Golder W, Gromnica-Ihle E, et al. Treatment of active ankylosing spondylitis with infliximab: a randomised controlled multicentre trial. Lancet 2002;359:1187-93.

[5] Videm V, Cortes A, Thomas R, Brown MA. Current smoking is associated with incident ankylosing spondylitis--the HUNT populationbased Norwegian health study. J Rheumatol 2014;41:2041-8.

[6] Wendling D, PratiC. Spondyloarthritis and smoking: towards a new insight into the disease. Expert Rev Clin Immunol 2013;9:511-6.

[7] Mattey DL, Dawson SR, Healey EL, Packham JC. Relationshipbetween smoking and patient-reported measures of disease outcome in ankylosing spondylitis. J Rheumatol 2011;38:2608-15.

[8] Zhao S, Challoner B, Khattak M, Moots RJ, Goodson NJ. Increasing smoking intensity is associated with increased disease activity in axial spondyloarthritis. Rheumatol Int 2017;37:239-44.

[9] Calin A, Nakache JP, Gueguen A, Zeidler H, Mielants H, Dougados M. Defining disease activity in ankylosing spondylitis: is a combination of variables (Bath Ankylosing Spondylitis Disease Activity Index) an appropriate instrument? Rheumatology 1999;38:878-82.

[10] Jenkinson TR, Mallorie PA, Whitelock HC, Kennedy LG, Garrett SL, Calin A. Defining spinal mobility in ankylosing spondylitis (AS). The Bath AS Metrology Index. J Rheumatol 1994;21:1694-8.

[11] Calin A, Garrett S, Whitelock H, Kennedy LG, O'Hea J, Mallorie $\mathrm{P}$, et al. A new approach to defining functional ability in ankylosing spondylitis: the development of the Bath Ankylosing Spondylitis Functional Index. J Rheumatol 1994;21:2281-5.

[12] Nemeth R, Smith F, Elswood J, Calin A. Ankylosing spondylitis an approach to measurement of severity and outcome: ankylosing spondylitis assessment questionnaire (ASAQ) - a controlled study. Br J Rheumatol 1987;26 (suppl 1):69-70.

[13] Doward LC, Spoorenberg A, Cook SA, Whalley D, Helliwell PS Kay LJ, et al. Development of the ASQoL: a quality of life instrument specific to ankylosing spondylitis. Ann Rheum Dis 2003;62:20-6.

[14] McHorney CA, Ware JE Jr, Raczek AE. The MOS 36-Item ShortForm Health Survey (SF-36): II. Psychometric and clinical tests of validity in measuring physical and mental health constructs. Med Care 1993;31:247-63.

[15] Moll JM, Wright V. An objective clinical study of chest expansion.
Ann Rheum Dis 1972;31:1-8

[16] Ekedahl H, Jönsson B, Frobell RB. Fingertip-to-floor test and straight leg raising test: validity, responsiveness, and predictive value in patients with acute/subacute low back pain. Arch Phys Med Rehabil 2012;93:2210-5

[17] Beck AT, Steer RA, Garbin MG. Psychometric properties of the Beck Depression Inventory: twenty-five years of evaluation. Clinical Psychology Review 1988;8:77-100.

[18] Fagerström KO. Measuring degree of physical dependence to tobacco smoking with reference to individualization of treatment. Addict Behav 1978;3:235-41.

[19] Moscato U, Poscia A, Gargaruti R, Capelli G, Cavaliere F. Normal values of exhaled carbon monoxide in healthy subjects: comparison between two methods of assessment. BMC Pulm Med 2014;14:204.

[20] Jones GT, Ratz T, Dean LE, Macfarlane GJ, Atzeni F. Disease severity in never smokers, ex-smokers, and current smokers with axial spondyloarthritis: results from the Scotland Registry for Ankylosing Spondylitis. Arthritis Care Res (Hoboken) 2017:69:1407-13.

[21] Zhang S, Li y, Xu X, Feng X, Yang D, Lin G. Effect of cigarette smoking and alcohol consumption on disease activity and physical functioning in ankylosing spondylitis: a cross-sectional study. Int J Clin Exp Med 2015;8:13919-27.

[22] Wang M, Wang S, Zhang X, Xia Q, Cai G, Yang X, et al. Analysis on the situation of subjective well-being and its influencing factors in patients with ankylosing spondylitis. Health Qual Life Outcomes. 2016;14:118

[23] Kaan U, Ferda O. Evaluation of clinical activity and functional impairment in smokers with ankylosing spondylitis. Rheumatol Int $2005 ; 25: 357-60$

[24] Sakellariou GT, Anastasilakis AD, Kenanidis E, Potoupnis M, Tsiridis E, Savvidis M. The effect of smoking on clinical and radiographic variables, and acute phase reactants in patients with ankylosing spondylitis. Rheumatol Int 2015;35:2109-14.

[25] Chung HY, Machado P, van der Heijde D, D'Agostino MA, Dougados M. Smokers in early axial spondyloarthritis have earlier disease onset, more disease activity, inflammation and damage, and poorer function and health-related quality of life: results from the DESIR cohort. Ann Rheum Dis 2012;71:809-16.

[26] Chen CH, Chen HA, Lu CL, Liao HT, Liu CH, Tsai CY et al. Association of cigarette smoking with Chinese ankylosing spondylitis patients in Taiwan: a poor disease outcome in systemic inflammation, functional ability, and physical mobility. Clin Rheumatol 2013;32:65963.

[27] Averns HL, Oxtoby J, Taylor HG, Jones PW, Dziedzic K, Dawes PT. Smoking and Outcome in Ankylosing Spondylitis. Scand J Rheumatol 1996;25:138-42.

[28] Bodur H1, Ataman S, Rezvani A, Buğdaycı DS, Cevik R, Birtane $\mathrm{M}$ et al. Quality of life and related variables in patients with ankylosing spondylitis. Qual Life Res 2011;20:543-9.

[29] Esen SA, Esen I, Karabulut Y, Atmiş V. Effects of the disease characteristics and the treatment on psychological status in patients with rheumatoid arthritis and ankylosing spondylitis. Curr Rheumatol Rev 2017 Jul 28. doi: 10.2174/1573397113666170728123518.

[30] Park SJ, Kim JH, Pai KS, Shin JI. The link of HLA-B27 with interleukin-23/interleukin-17 axis in coexisting systemic lupus erythematosus and ankylosing spondylitis. Lupus 2011;20:1566.

[31] Jamalyaria F, Ward MM, Assassi S, Learch TJ, Lee M, Gensler LS, et al. Ethnicity and disease severity in ankylosing spondylitis: a crosssectional analysis of three ethnic groups. Clin Rheumatol 2017;36:2359-64 